\title{
Treatment of Parkinson's disease with agents other than Levodopa and Dopamine Agonists: controversies and new approaches
}

\author{
Anthony E. Lang
}

\begin{abstract}
Parkinson's disease is associated with a variety of neurotransmitter disturbances which may be further altered by its treatment with dopamine agonists. Based on this information a wide range of pharmacological approaches have been used in search of newer treatment alternatives and in hopes of reducing complications of long-term levodopa use. This paper reviews the various therapies which have had some success in the management of Parkinson's disease, other than levodopa and dopamine agonists. Special emphasis is placed on the many unresolved questions and controversies that exist in this area of neuropharmacology.
\end{abstract}

RÉSUMÉ: La maladie de Parkinson s'associe à une variété de modifications des neurotransmetteurs et ceux-ci peuvent être encore plus altérés par le traitement avec les agonistes de la dopamine. De nombreuses approches pharmacologiques ont été utilisées afin d'offrir de nouvelles alternatives thérapeutiques et afin de réduire les complications à long terme de la Lévodopa. Nous revoyons les diverses thérapies utiles autres que la Lévodopa et les agonistes de la dopamine. Nous insistons surtout sur les questions et contreverses qui persistent.

Can. J. Neurol. Sci. 1984;11:210-220

The treatment of Parkinson's disease has probably included a greater variety of pharmacological approaches than with any other neurologic condition. Despite these multiple therapeutic attempts, there exist only a few noncontentious findings most notably the marked efficacy of levodopa. In this paper I will review the treatment of Parkinson's disease with agents other than levodopa and direct acting dopamine agonists emphasizing the controversies that may exist. This will include older forms of therapy such as amantadine and anti-cholinergics, other more experimental anti-Parkinsonian agents which may be useful as levodopa adjuvants and drugs that may be helpful in the treatment of side effects occurring with levodopa and dopamine agonists.

\section{Amantadine}

\section{Mechanism of Action}

Since the chance discovery by Schwab and collegues (1969) of the beneficial effects of amantadine $\mathrm{HCl}$ in Parkinson's disease the mechanism of action of this drug has remained ill defined and controversial. Many studies favour an effect related to the augmentation of dopamine (DA) release, inhibition of cellular re-uptake and possibly increased DA synthesis (Parkes, 1974). Microiontophoretic studies, however, show that it has some function independent of catecholaminergic activities (Stone, 1977). Despite animal studies which demonstrate little or no anti-cholinergic action (Gerlak et al., 1970), a strong clinical argument can be made for amantadine having prominent anticholinergic effects. The brief review of the clinical literature to follow unfortunately does not resolve this dispute.
Anti-cholinergic-like side effects such as dry mouth, constipation, difficulty focusing and urinary retention are not infrequent with chronic amantadine therapy. These complications may be additive with those of the anti-cholinergic drugs and some authors suggest that a temporary reduction in anti-cholinergics may be useful during the initiation of amantadine (Schwab et al., 1972). Also favouring anti-cholinergic action is the demonstration that signs of acute intoxication with amantadine (given with haloperidol in one case) can be reversed with physostigmine (Casey, 1978).

Several clinical points favour different pharmacological actions for amantadine and anti-cholinergic agents. Although both produce a similar degree of improvement in the total disability of Parkinson's disease (Schwab and England, 1969) had initially felt that amantadine was slightly more effective), in a comparative study, the response of individual features of the disease was different (Parkes et al., 1974). Anti-cholinergics had a major effect on rigidity and postural deformity while amantadine improved all symptoms of Parkinsonism. In addition, the combination of amantadine plus anti-cholinergics was more effective than the sum of the individual drug responses. Although amantadine results in atropine-like effects the incidence of these is less than with anti-cholinergics such as benzhexol. In addition, amantadine alone results in the distinctive side effects in livido reticularis and ankle edema. It has been proposed that these latter complications reflect local release of vasoconstrictor catecholamines and secondary abnormal permeability of dermal blood vessels (Parkes et al., 1973). Finally, although amantadine and anti-cholinergics have been found to have comparable effects in relieving the signs of drug-induced parkinsonism, DiMascio et al. (1976) found that when amantadine was given

From the Division of Neurology, Toronto Western Hospital, Toronto, Ontario

Reprint requests to: Dr. A.E. Lang, Division of Neurology, Toronto Western Hospital, 25 Leonard Ave., Toronto, Ontario, Canada M5T 2R2 
with neuroleptics in schizophrenics the improvement in psychiatric symptoms occurred at a slower rate than in those receiving benztropine. This may be further evidence for amantadine having an effect on dopaminergic mechanisms.

The signs of amantadine overdose in one patient unfortunately contribute to the conflict rather than resolve it. Fahn et al., (1971) described a patient who took a total of 2.8 grams of amantadine in a suicide attempt. He developed an acute toxic psychosis with a mixed acid-base disturbance. The patient had anti-cholinergic-like features such as urinary retention and pupils which were barely reactive to light. Unlike atropinized patients, however, the pupils were only slightly dilated and the skin moist.

One can conclude from the above that amantadine has a mixture of effects on dopaminergic and non-dopaminergic systems. It is unlikely that the beneficial response in Parkinson's disease obtained with amantadine is solely due to either presynaptic dopaminergic mechanisms or anti-cholinergic effects.

\section{Other indirect dopaminergic agonists}

A further possible argument in favour of amantadine having additional non-dopaminergic activity is the disappointing response seen in trials with a variety of drugs known to block the re-uptake of catecholamines. Amphetamines were widely used in the early treatment of post-encephalitic Parkinsonism (Davis and Stewart, 1938). Although these drugs had a dramatic effect on oculogyric crises and patients experienced an improvement in mood, energy and sleep disorders, there was little or no improvement in the symptoms of Parkinsonism.

Amphetamines, methlyphenidate and other stimulant drugs were said to be useful in patients with idiopathic Parkinsonism who became drowsy or dull as a result of other therapy (Schwab, 1961). However most clinicians have had little success with this approach. In the treatment of parkinsonism, methlyphenidate has been found to have no more than mild beneficial effects (Halliday and Nathan, 1961). D and L-amphetamine resulted in only minimal changes in parkinsonism with the frequent occurrence of side effects (Parkes et al., 1975) which were dissimilar to those occurring with amantadine as documented by the same group (Parkes et al., 1974).

Nomifensine, a tetrahydroisoquinoline anti-depressant somewhat different from the classic tricyclic compounds has been shown to block the uptake mechanism of catecholamines, particularly dopamine (Hunt et al., 1974). Studies using doses of $25-150 \mathrm{mg}$ have obtained little effect in Parkinson's disease (Bédard et al., 1977; Barbeau et al., 1979); however two studies found it of some benefit in slightly higher doses when given both with (Teychenne et al., 1976) and without (Park et al., 1981) concommitant levodopa therapy.

Diprobutine, a tripropylmethylamine without anti-cholinergic activity, prepared as an anologue of amantadine, potentiates the behavioural effects of apomorphine and amphetamine in animals and may also increase dopamine turn-over (Broll et al., 1977). Preliminary studies by Barbeau et al. (1979) showed a prolongation of the effect of a single dose of levodopa by diprobutine however increased doses resulted in a re-emergence of parkinsonian symptoms in addition to frequent side effects.

Recently bupropion $\mathrm{HCl}$ resulted in mild clinical benefit but frequent side effects (Goetz et al., 1983). This is normally an effective antidepressant however only one of eight patients with Parkinson's disease and depression had an improvement in their mood.

Pemoline mesylate is an oxolidine compound with central stimulant effects used to treat children with minimal brain dysfunction. Although structurally different from d-amphetamine and methylphenidate it is thought to act in a similar manner by increasing central dopaminergic activity. Recent reports have described choreiform involuntary movements occurring with acute (Nausieda et al., 1981) and chronic (Singh et al., 1983) use. Nausieda and collegues demonstrated effects similar to other dopaminergic up-take blockers. Behavioural responses to dopamine agonists were enhanced with chronic treatment suggesting an increase in post-synaptic striatal dopaminergic sensitivity. To date no trials of pemoline in Parkinson's disease have been reported however one might expect little difference from previous trials using this general group of drugs.

Recently two other approaches have been used in an attempt to increase the amount of dopamine available for release by nigral neurons. Tryrosine, the physiological precursor of catecholamine synthesis, resulted in some anti-Parkinsonian effects however these were mild and limited to patients with disease of recent onsent (Growden, 1981). Tryrosine hydroxylase (TH) the rate limiting enzyme in the synthesis of catecholamines is markedly decreased in the brains of patients with Parkinson's disease (Nagatsu et al., 1979) and biopterin, the co-factor for TH is equally reduced (Narabayashi et al., 1982). Narabayashi and his colleagues obtained a mild to moderate improvement in the signs of Parkinsonism, particularly akinesia, in 5 patients with a singie dose of tetrahydrobiopterin $\left(\mathrm{BH}_{4}\right)$. The potential synergistic effects of combining $\mathrm{BH}_{4}$ and tyrosine would be of great interest for future study.

\section{Anti-cholinergic Drugs}

From the late 1860's when Ordenstin (1867) a student of Charcot fortuitously discovered the response to bellodonna alkaloids, to the time levodopa was introduced in the 1960's, anti-cholinergic agents remained the only useful drug treatment for Parkinson's disease. At one time, stramonium, often administered in the form of cigarettes, was thought to be the most potent agent. Atropine and hyocine were the most widely used of the natural alkaloids until synthetic anti-cholinergic and anti-histaminic agents were introduced in the 1940's. Despite the wide-spread and long-term use of these agents several questions concerning their effects remain.

\section{Pharmacokinetics}

The pharmacokinetics of one of this group of drugs has only recently been studied. Burke and Fahn (1982) found that the half-life of trihexyphenidyl was $1.7 \pm 0.2$ hours in normal volunteers receiving an acute dose while in dystonic patients on higher doses the $T_{1 / 2}$ was $3.7 \pm 0.3$ hours. In volunteers, cerebral side effects (lethergy and confusion) correlated more closely with age than with peak serum levels. Although studies of patients with Parkinson's disease have not been done, these results suggest that a more frequent dosage schedule than the usual 3 times per day might be more beneficial however side effects would almost certainly supervene in many.

\section{Mechanism of action}

The mechanism of action of the anti-cholinergics remains unsettled. It is clear that the greatest part of their effect relates 
to the ability of these agents to block central muscarinic acetylcholine receptors (Duvoisin, 1967). However studies have shown that certain anti-cholinergic drugs, particularly benztropine, have an effect on blocking dopamine uptake in central dopaminergic neurons (Farnebo et al., 1970) and in striatal synaptosomal fractions (Coyle and Snyder, 1969). Whether this effect on presynaptic dopamine mechanisms is important to the action of synthetic anti-cholinergic drugs is not known. In the pre-Ldopa era, one anti-cholinergic was often chosen over another depending on the degree of tremor or rigidity the patient demonstrated. However, there have been no double-blind crossover trials comparing different anti-cholinergics in Parkinson's disease. In open trials Schwab and Chafety (1955) found that procyclidine was slightly (13\%) more effective than benztropine, contrary to the results predicted from dopamine up-take studies. It is the general experience of most clinicians now that individual patients may tolerate and benefit from one anti-cholinergic more than another without predictability. Some authors find that benztropine is less well tolerated (Hurtig, 1980) and others have had better results with one particular drug more than others (for example ethopropazine - Fahn, 1982).

\section{Activity}

It is interesting that many clinicians now consider early treatment with anti-cholinergic drugs particularly in patients with tremor. Before levodopa these drugs were thought to be most effective against rigidity (Schwab, 1961; Strange, 1965). In a double-blind study Strange (1965) found that procyclidine was "much more effective in reducing rigidity than in diminishing tremor" while in a further study (Strange, 1965a) he found benztropine only slightly more effective against tremor than against rigidity. More recently Parkes et al. (1974) found that benzhexol was most effective against postural deformity and rigidity. It has been the experience of most authors that akinesia responds extremely poorly to anti-cholinergic agents.

Although the benefit obtained from anti-cholinergics is usually only mild or moderate, two thirds of patients are unable to tolerate anti-cholinergic withdrawal despite continued levodopa therapy (Hughes et al., 1971; Horrocks et al., 1973). Dopaminergic drugs may be stopped for "drug holiday" without tapering. Acute withdrawal of anti-cholinergic drugs however, often results in a sudden marked exacerbation of parkinsonian symptoms (Goetz et al., 1981). This suggests that long-term anti-cholinergic use might induce acetylcholine-receptor hypersensitivity which could result in a much greater deterioration in symptoms on drug withdrawal than would have been expected from the magnitude of the initial beneficial response. That anti-cholinergics can account for at least a part of this effect is suggested by the finding of greater muscarinic acetylcholine receptor densities in frontal cortex in patients who had received anti-cholinergic therapy (Ruberg et al., 1982, see below). It is likely that similar changes ocurr in striatal cholinergic receptors.

Long-term L-dopa therapy may also be associated with cholinergic hypersensitivity. Weintraub and VanWoert (1971) documented that early in the course of levodopa therapy physositigmine no longer increases the signs of Parkinsonism as it does in untreated patients (Duvoisin, 1967). Recently, Yahr et al. (1982) studied patients with fluctuations associated with long-term levodopa therapy. They found that physostigmine resulted in the initiation of an "off" period similar to the results documented by Duvoisin (1967) in L-dopa naive patients. It is likely, therefore, that the long term use of both levodopa and anti-cholinergics contributes to the return of cholinergic sensitivity seen in late-stage Parkinsonism.

\section{Psychiatric/Psychologic effects}

The psychiatric side-effects of anti-cholinergics have long been recognized as a major limiting factor to their use, particularly in the aged. Cholinergic systems most notably that originating in the neurons of the nucleus basalis of Meynert (Whitehouse et al., 1981) are now known to be of importance to memory and in the manifestations of Alzheimer's disease (Davies and Maloney, 1976). Ruberg et al. (1982) have documented a deficiency of cholinergic innervation in frontal cortex of parkinsonian subjects similar to that seen in Alzheimer's disease. The degree of this deficiency showed a correlation with a retrospective analysis of the patient's pre-morbid intellectual impairment (Ruberg et al., 1982). A loss of cholinergic neurons in the nucleus basalis similar to that first described in Alzheimer's disease has also been found in demented parkinsonian patients (Whitehouse et al., 1983).

A toxic confusional state is a frequent side effect of anticholinergics in patients with pre-existing intellectual dysfunction. De Smet et al. (1982) found the occurrence of such states to be almost universal in demented Parkinsonians. ${ }^{1}$ Anti-cholinergics have also been found to impair intermediate and delayed recall in non-demented Parkinsonian patients (Syndulko et al., 1981; Sadeh et al., 1982) and we have found improvements in both short-term and long-term memory in patients withdrawn from anti-cholinergic agents (Figure 1). These findings suggest that anti-cholinergics should not be used in patients with pre-existing intellectual impairment and that physicians should be aware of the possible subtle psychological changes that may be produced by these drugs even in patients with normal mentation. Whether anti-cholinergics could contribute to the damage of cholinergic neurons in demented patients is not known. To date the only morphologic alterations documented which are probably due to anti-cholinergic use are the changes in cortical acetylcholine receptor densities mentioned above.

\section{Cholinergic Agonists}

\section{Levodopa dyskinesias}

Based on the long standing "balance hypothesis" of acetylcholine and dopamine in the pharmacology of Parkinson's disease it has been proposed that a relative cholinergic under-activity could contribute to hyperkinetic movement disorders such as L-dopa-induced dyskinesias, tardive dyskinesia and Huntington's chorea (Klawans and Rubovits, 1972). Anticholinergic withdrawal in one study resulted in an improvement in levodopa-induced involuntary movements in nine out of ten patients (Horrocks et al., 1973). Tarsy et al. (1973) found that physositigmine improved dyskinesias; however, as seen with anti-cholinergic withdrawal, parkinsonian symptoms worsened. Deanol, a questionable acetylcholine percursor, was then reported to be extremely effective in reducing levodopa-induced dyskinesias (Miller, 1974); however subsequent studies (Klawans et al., 1975; Lindeboon and Lakke, 1978) failed to reproduce this finding. Choline

1. Stern (1980) has suggested that intravenous physostigmine could be used to determine the degree to which anti-cholinergics are contributing to the confusional state as an alternative to gradually weaning oral medication. 


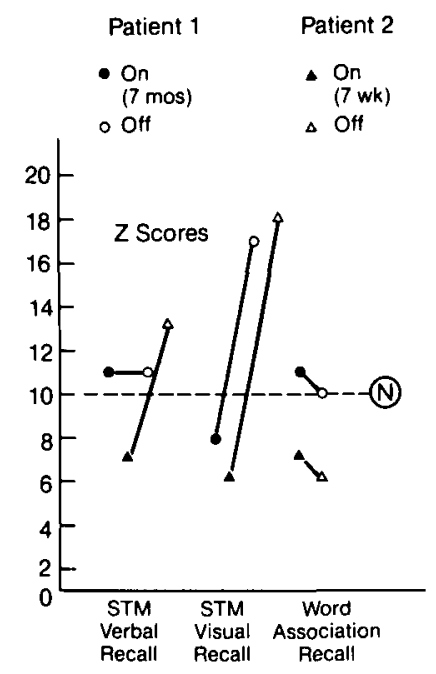

- $\triangle$ WMS (I), RAVLT (C)

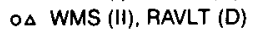
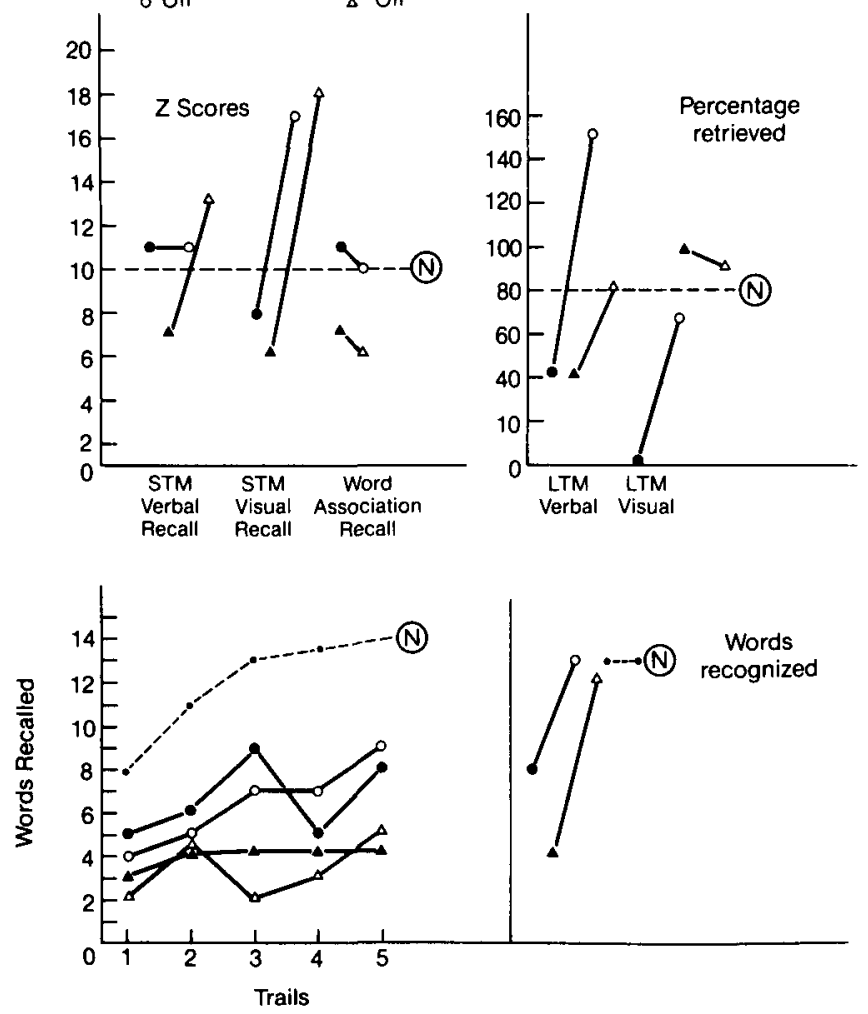

Figure 1 - Memorytests results in 2 patients before and after anticholinergic withdrawal. Patient I ( 7 months between tests) had no improvement in short-term memory (STM) verbal recall but had a striking improvement in STM visual recal and in long-term memory (LTM) visual and verbal recall, remembering more details of the story passage than he could in the immediate post-trial period (reason for percentage retrieval $>100 \%$ in upper right graph). Patient 2 ( 7 weeks between tests) had an improvement in STM verbal and visual recall as well as LTM verbal recall. Neither patient showed improvements in tests which require the formation of stratagies to facilitate verbal learning as seen in Word Association testing (Paired Auditory Learning Tests of the Wechsler Memory Scale) (see top left graph) and in a verbal acquisition test (Rey Auditory Verbal Learning Test (RAVLT)) (lower left graph). In the latter test, although the patients showed no improvement in sponteneous retrieval with repeated presentations (trials), their ability to recognize presented words after the test was complete improved markedly (demonstrating that learning did occur) with anticholinergic withdrawal (lower left graph).WMS $(I) /(I I)=$ Wechsler Memory Scale forms I and II. RAVLT $(C) /(D)=$ Rey Auditory Learning Test forms $C$ and $D$.

chloride, a compound which produces a well documented increase in brain acetylcholine, has had little effect on levodopa dyskinesias in doses in 200 -300 mg per kilogram per day (Papavasiliou and Rosal, 1979). Barbeau (1979) found that lecithin (phosphatidylcholine) in a dosage of 20 grams per day produced a marked reduction in the number and severity of levodopa-induced dyskinesias but at the expense of a return of "some degree" of rigidity and akinesia. There was no improvement in the "on-off" phenomenon (Barbeau et al., 1979). Therefore, the usefulness of increasing brain acetylcholine activity in patients with L-dopa dyskinesias is probably limited.

\section{Dementia}

Trials of cholinergic agonists in Alzheimer's disease have had disappointing results. To date no similar studies have been performed in the dementia of parkinsonism. Despite the similarities in the pathology and biochemistry of the dementia seen in Parkinson's disease and Alzheimer's disease (Whitehouse et al., 1983), clinical differences are well recognized (Albert, 1978). Therefore negative results in trials of cholinergic agonists in the dementia of Alzheimer's disease may not reliably predict failure in Parkinsonians with intellectual deterioration. However one would expect from the studies quoted above that the signs of parkinsonism would increase during such a trial.

A final, theoretical use for cholinergic agonists might be in hopes of improving the response to levodopa. Levodopa drug holidays often precipatate marked exacerbations in parkinsonian symptoms with multiple potential complications. It may be possible to "resensitize" the parkinsonian loss of response to levodopa by giving cholinergic agonists while maintaining L-dopa therapy. Such an approach might avoid the extreme forms of deterioration sometimes seen in patients discontinuing L-dopa. This therapeutic intervention could affect dopaminergic activity and thus possibly receptor sensitivity through either cholinergic feedback interneurones in the striatum or through alteration in the activity of the long striatonigral feedback pathways. The possibility of such an alteration with this therapeutic approach is purely a matter of conjecture at present.

\section{Deprenyl}

Birkmayer and Hornykiewicz (1962) first used the standard available monoamine oxidase inhibitors in an attempt to increase the effectiveness of levodopa by blocking the oxidative deamination of dopamine. Although clinical improvement has been documented with this approach, side effects are frequent. One of the greatest concerns is the possibility of provoking an acute hypertensive crisis ("cheese effect") (Hunter et al., 1970). It is now known that monamine oxidase exists in at least two forms. MAO type A metabolizes serotonin, noradrenaline, octopamine, tyramine and to a lessor extent dopamine. MAO-B oxidatively deaminates phenylethylamine, tyramine, benzylamine and dopamine (Sandler and Youdim, 1974). (-) deprenyl is a selective MAO-B inhibitor" free of the "cheese (side) effect" "2 which has been used in therapeutic trials in parkinsonism since 1975 (Birkmayer et al., 1975). Despite the many studies published on the use of this drug the mechanism of action and the response to therapy remain controversial.

\section{Mechanism of Action}

Deprenyl completely blocks the activity of monamine oxidase $B$ in platelets but whether the central MAO blocking effect is clinically significant is a matter of debate. Deprenyl is efficiently and rapidly converted to methamphetamine and amphetamine (Reynolds et al., 1978; Karoum et al., 1982) and the effects of these indirect catecholamine agonists plus deprenyl's own ability to block the uptake of biogenic amines, especially tyramine and dopamine (Knoll, 1978), may be more important than effects on MAO-B (Karoum et al., 1982). Phenylethylamine (PEA) is a preferred substrate for MAO-B (Yang and Neff, 1973). Birkmayer et al. (1977) suggested that PEA, which has a marked ampheta-

1. Chronic use of (-) deprenyl may also result in cumulative MAO-A inhibition (cf Sandler and Stern, 1981).

2. See Sandler and Stern (1981) for discussion of the pharmacological mechanism of the "cheese effect" and the reasons why (-) deprenyl may be devoid of this complication. 
mine-like effect, might have been responsible for the potentiation of the effects of L-dopa induced by deprenyl in their patients. However, Karoum et al. (1982) found that the addition of deprenyl to Sinemet therapy produced changes in the urinary output of catecholamines, PEA, $\mathrm{m}$ - and p-tyramine and their metabolites that could not be accounted for solely by the inhibition of MAO-B in the central nervous system.

\section{Activity}

The results of clinical trials using deprenyl in Parkinson's disease vary greatly. Birkmayer and his colleagues (see Birkmayer et al., 1982 for review) have demonstrated a significant and prolonged potentiation of the response to levodopa (given with benserazide) in both early and long-standing disease. They also obtained an improvement in patients who had lost previous clinical response to L-dopa. Others report that deprenyl has a limited beneficial effect which could be explained by a simple alteration in mood (Eisler et al., 1981). ${ }^{1}$ Indeed, deprenyl has been shown to have significant anti-depressants effects compared to placebo in non-parkinsonian depressed patients (Mendlewicz and Youdim, 1983).

The effect of deprenyl in patients with fluctuations in their clinical state on levodopa has also been quite variable. Some authors reported that two thirds of patients obtain a significant amelioration in the degree of oscillation (Yahr, 1978; Rinne et al., 1978) with all patterns of fluctuation improving. Others (Lees et al., 1977; Schacter et al., 1980) have found deprenyul only useful in improving dose-related fluctuations ("end-ofdose akinesia" or "wearing off") while the severity of response swings often worsen in patients with random fluctuations ("on-off' phenomenon) (Schacter et al., 1980). Noctural and early morning akinesia have improved but freezing is unaffected (Lees et al., 1977). Patients originally studied by Lees and colleagues who had remained on deprenyl for up to $\mathbf{3 0}$ months had the drug replaced by placebo in a double-blind fashion. About two thirds showed some deterioration but only $21 \%$ (4 of 18) had been benefitting substantially (Stern, 1980).

Deprenyl is presently unavailable for general use. Although it seems that this drug may be useful in patients with doserelated fluctuations, its final role as an adjuvant to levodopa in the treatment of Parkinson's disease remains to be determined.

\section{COMT Inhibition}

Levodopa is metabollized in part by catechol-0-methyl transferase (COMT) to the methylated derivitive 3-0 methyldopa (OMD). OMD given with levodopa results in an increase in parkinsonian signs (Calne et al., 1972; Muenter et al., 1974). Due to its long half-life OMD accumulates in the plasma and CSF of patients treated with levodopa (Sharpless and MacCann 1971, Muenter et al., 1972) and high levels of OMD are found in some patients who are responding poorly to L-dopa (RiveraCalimlim et al., 1977). The accumulation of OMD has therefore been implicated in the poor responses to levodopa seen with chronic treatment. This effect could be due to the ability of OMD to compete with L-dopa and tyrosine for the blood brain

\footnotetext{
1. Sandler and Stern (1981) question whether Eisler et al. (1981) could have been using $(+)$ deprenyl, which has a much greater amphetamine-like effect, rather than (-) deprenyl. This might explain the marked difference in clinical effects and the frequency of mood elevation and insomnia reported by Eisler and his colleagues in comparison to other groups.
}

barrier carrier mediated transport system for aromatic amino acids (Reches \& Fahn 1982, Gervas et al., 1983). N-butylgallate, a COMT inhibitor, was found to have a synergistic effect with levodopa in a small group of patients with Parkinson's disease (Ericsson 1971) however the drug was withdrawn because of its toxicity. The development of safer COMT inhibitors, therefore, remains another potential adjuvant to levodopa particularly in those who are not responding well to such treatment. The overall poor response of these patients to the newer direct-acting dopamine agonists, however, suggests that OMD contributes only partially to levodopa's loss of efficacy.

\section{Dopamine Antagonists}

\section{Domperidone}

Domperidone is a peripheral DA receptor antagonist which crosses the blood brain barrier in only minute amounts. "Peripheral" side effects of direct acting DA agonists (eg. apormorphine, bromocriptine, lisuride, pergolide) may be prevented when domperidone is given with these agents analogous to the addition of peripheral decarboxylase inhibitors to levodopa (Agid et al., 1981). It may also be useful in patients who experience persistant levodopa-induced gastrointestinal side effects despite supplimentary carbidopa or benserazide. Postural hypotension complicating DA agonist therapy may not be avoided by the use of domperidone suggesting that this side effect is primarily of central origin (Agid et al., 1981).

\section{$\mathrm{DA}_{2}$ Receptor antagonists}

It is possible that some of the central side effects of levodopa and other DA agonists could be due to stimulation of DA receptors of a different type from those which account for the anti-parkinsonian activity of these drugs. When standard neuroleptic drugs such as the phenothiazines (eg. chlorpromazine) or the buterophenones (eg. haloperidol) are given to patients with L-dopa-induced dyskinesias the involuntary movements improve at the expense of an unacceptable increase in parkinsonism. In contrast to the activity of other neuroleptics the substituted benzamides (eg. metoclopramide, oxiperamide, tiapride, sulpiride) fail to antagonize DA stimulated elevations of striatal adenylate/cyclase activity (Jenner et al., 1978) (ie. block only " $\mathrm{DA}_{2}$ "' receptors). Trials of metoclopramide (Tarsy et al., 1975a), oxiperamide (Bedard et al., 1978a) and tiapride (Lhermitte et al., 1977; Price et al., 1978a; Lees et al., 1979) in patients with L-dopa-induced dyskinesias have met with variable success. The King's College group found that although oxiperamide (Tarsy et al., 1975a) and tiapride (Price et al., 1978a) frequently caused a deterioration in Parkinsonian disability in addition to reducing involuntary movements, the former effect could be balanced by an increase in DA agonist therapy (L-dopa or bromocriptine) often without a concomittant increase in dyskinesias. This response might suggest that stimulation of the $\mathrm{DA}_{2}$ receptor is more closely related to the development of dyskinesias than to the improvement of parkinsonian signs. However, when Price et al. (1981) compared sulpiride, a $\mathrm{DA}_{2}$ receptor antagonist, with cisflupenthixol, a non-selective $\mathrm{DA}_{1}$ and $\mathrm{DA}_{2}$ receptor antagonist, they found no difference in their ability to inhibit the anti-Parkinsonian action of L-dopa or the associated drug-induced dyskinesias. These results could indicate “that $\mathrm{DA}_{1}$ receptors are not of great importance in Parkinson's 
disease and dyskinesias, or that the distinction between $\mathrm{DA}_{1}$ and $\mathrm{DA}_{2}$ is artificial."' (Price et al., 1981).

$\mathrm{DA}_{2}$ antagonists also might be useful in controlling psychiatric side effects of levodopa and other DA agonists. Occasionally a small dose of a standard neuroleptic with a low incidence of extrapyramidal side effects, such as thioridazine (Mellaril), may control the psychiatric features without an associated disabling increase in Parkinsonism. This approach is best reserved for patients in whom either a reduction in the DA agonist dosage or a drug holiday have been unsuccessful.

\section{Noradrenergic Agents}

Parkinson's disease is well known to affect other pigmented brain stem neuclei such as the locus ceruleus (Greenfield \& Bosanquet 1953). Noradrenaline (NA) is reduced in Parkinsonian brains and levodopa treatment seems to result in a trend towards higher levels (Rinne \& Sonninen 1973). Dopamine- $\beta$-hydroxylase, which converts DA to NA is also reduced in the brain (Nagatsu et al., 1979) and CSF (Narabayashi et al., 1981) of patients with Parkinson's disease. How NA deficiency contributes to the clinical features of parkinsonism remains a mystery. Several drugs that potentiate catecholamine (DA and NA) mechanisms have been discussed in the section on amantadine and other indirect dopamine agonists. Noradrenergic precursors given alone are said not to affect the features of Parkinson's disease (Birkmayer and Hornykeiwicz, 1962). Tarsy et al. (1975) found that clonidine hydrochloride, a central noradrenergic agonist, did not improve signs of Parkinsonism and had no effect on response fluctuations. Narabayashi et al. (1981) have recently shown a striking response of freezing and micrographia to the noradrenaline precursor L-threo- 3, 4 dihydroxyphenylserine (L-threo-DOPS) given with a peripheral decarboxylase inhibitor. Akinesia, rigidity and tremor were also slightly improved. Further trials using this novel agent will be most important since freezing in late-stage Parkinsonism is particularly resistant to standard therapy. Given without a decarboxylase inhibitor, L-threoDOPS increases peripheral NA levels (Reches et al., 1983). This may be useful in patients with parkinsonism and orthostatic hypotension (either idiopathic Parkinson's disease or Shy-Drager syndrome).

\section{Beta Adrenmergic Antagonists}

The postural tremor commonly present in Parkinson's disease may occasionally improve with propranolol as may the increase in resting tremor which occurs with anxiety or emotion (Owen \& Marsden 1965). Indeed, even rigidity and akinesia have been reported to respond to beta blockade (Gerstenbrand et al., 1979) however this is contrary to the experience of most physicians. Nadolol, a non-selective beta blocker which does not cross the blood brain barrier, has been reported to reduce resting, "sustention" and action tremors in Parkinson's disease

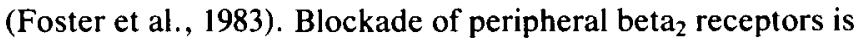
thought to account for much of the effect of beta blockers in essential tremor (Jefferson et al., 1979) and it remains to be elucidated whether a similar mechanism accounts for the response seen in Parkinsonism.

Patients treated with long-term levodopa may develop paroxysmal drenching sweats often associated with excessive warmth, non-specific malaise, anxiety or lightheadedness (Tanner et al., 1982). These symptoms, which can occur in the "on" phase in association with dyskinesias (Klawans, 1982) or during the "off' phase with marked akinesia (Lang, personal observation) may respond particularly well to propranolol. Klawans (1982) has also found that the addition of carbidopa in patients taking L-dopa alone may partially relieve such symptoms occuring in the "on" periods.

\section{Serotonergically Active Agents}

\section{Parkinsonism}

Levels of serotonin in Parkinson brains have been significantly reduced in some reports (Fahn et al., 1971a) although others have found only slight, insignificant changes (Rinne et al., 1974). Mayeux and his colleagues (1983) have recently reported that CSF levels of 5 hydroxyindoleacetic acid (5 HIAA) are significantly lower in a subgroup of depressed parkinsonians than in those without depression. Levodopa also seems to reduce cerebral serotonin levels further (Karobath et al., 1971). In animals, lesions in the upper brain stem associated with a reduction in striatal serotonin levels result in a tremor which is ameliorated by raising the brain serotonin level (cf Chase, 1974). Preliminary studies in Parkinson's disease suggested that serotonin precursors might be effective in improving tremor (Barbeau, 1962). However further studies demonstrated a pronounced worsening in parkinsonian signs with L-5 hydroxytryptophan (with a peripheral decarboxylase inhibitor) as well as L-tryptophan (given with pyridoxine). In levodopa treated patients, neither serotonin precursor significantly altered signs of parkinsonism or L-dopa-induced involuntary movements (cf Pelton and Chase, 1975).

\section{Psychiatric side effects}

Because levodopa may depress brain serotonin it has been proposed that central serotonergic suppression may account for the psychiatric side effects seen with this drug. Using L-tryptophan in patients with levodopa-induced psychosis Birkmayer and Neumayer (1972) obtained a clearing of the psychiatric features with a concommitant rise in CSF 5 HIAA. Although similar findings were reported by others (Miller and Neiburg, 1974), a double-blind placebo-controlled trial (Beasly et al., 1980) failed to confirm the response of psychiatric disturbances to tryptophan. However Bryant (1980) has suggested the existance of two groups of patients, those with a shorter duration of disease being more likely to respond to tryptophan.

Nausieda et al. (1983) have recently reported that methysergide, a serotonin antagonist, improves psychiatric complications as well as levodopa-induced myoclonus (an association which is not infrequent). They suggested that these side effects could be secondary to a long-standing reduction of serotonergic activity by levodopa resulting in central sertonergic sensitization, thus accounting for the response to methysergide. The psychiatric complications of levodopa and other dopamine agonists pose a major limiting factor to their use in late-stage parkinsonism. Further trials confirming this approach to therapy are therefore awaited with interest.

\section{Depression}

Tricyclic anti-depressants are often used in Parkinson's disease to control the depression that is so commonly present. Amitrip- 
tyline has also been reported to improve early sleep disorders such as prominent insomnia and day-time somnolence but worsen more severe degrees of sleep disruption (Nausieda et al., 1983). The anticholinergic effects of tricyclic anti-depressants may account for some improvement in parkinsonian signs however little if any additional benefit occurs in levodopa-treated patients (Pelton and Chase, 1975). Tricyclics should be used with caution in patients who have experienced significant side effects on anti-cholinergics and patients taking the latter agents should probably have them reduced or withdrawn at the time a tricyclic is started.

Several newer anti-depressants lacking anticholinergic activity are now available or under trial (see also section on "other indirect dopaminergic agonists"). Zimelidine is a potent antidepressant, structurally unrelated to the tricyclic and tetracyclic compounds. It is a relatively selective inhibitor of serotonin uptake with little anti-cholinergic or sedative effects (Heel et al., 1982). This may be a better choice in the treatment of depression in elderly parkinsonians or in those with a previous history of severe anti-cholinergic side effects. Mianserin is another investigational agent that could be useful in similar circumstances.

Tetrahydrobiopterin $\left(\mathrm{BH}_{4}\right)$ might also be useful in the depression of Parkinson's disease. Biopterin is the cofactor for both tyrosine and trytophan hydroxylases. The latter is the first enzyme in the synthetic pathway of serotonin from the amino acid tryptophan. Curtius and colleagues (1983) have reported a patient with depression (non-parkinsonian) refractory to standard drug therapy who improved markedly on $\mathrm{BH}_{4}$ given with supplemental trytophan. CSF content of 5HIAA, homovanillic acid (HVA) and biopterin all rose significantly while on this treatment.

In commenting on depression it should be mentioned that there is a great deal of interest in the possible effects of electroconvulsive therapy on the sensitivity of bioamine receptors. ECT has been reported to improve parkinsonian symptoms (Lebensohn and Jenkins, 1975; Asnis, 1977) as well as the "on off' phenomenon (Balldin et al., 1980).

\section{Lithium}

Coffey and his collegues (1982) recently reported that lithium carbonate improved the fluctuations of patients on levodopa. Basic investigations (Reches and Fahn, 1983) fail to support a theoretical reason for using lithium in these patients and, in a larger series, Liebermann and Gopinathan (1982) were unable to reproduce the original beneficial results. Of three patients with fluctuations treated with lithium that I have seen one had a marked but short lived improvement, one developed hallucinations and the third became more rigid and stuporose. In addition I have recently seen one patient with disabling parkinsonism on long term lithium in whom all Parkinsonian signs resolved after the drug was withdrawn (Lang, in press). Further clinical studies using lithium in Parkinson's disease must therefore be undertaken with great caution.

\section{GABA-ergic Drugs}

The content of gamma aminobutyric acid (GABA) is significantly reduced in cerebral and cerebellar cortex in the brains of parkinsonian patients and Rinnés group has found a significant correlation between the severity of tremor and the activity of glutamic acid decarboxylase (GAD) in the corpus striatum (Rinne, 1978). GABA receptor binding in the substantia nigra is also decreased (Lloyd et al., 1977). Recently, Iow CSF GABA levels has been found in patients who respond poorly to levodopa or who have the "on-off" phenomenon (Teychenne et al., 1982). Several putative GABA agonists have been used in the treatment of Parkinson's disease but with little benefit.

Baclofen is thought to have an effect on a presynaptic bicuculline-insensitive GABA receptor site (Bowery et al., 1980). Lees et al., (1978) obtained no improvement in 12 patients with $30-90 \mathrm{mg}$ of baclofen per day however rigidity increased and side effects were common. On the other hand, baclofen in doses of 5-40 mg may be extremely useful in reducing disabling foot dystonia associated with levodopa therapy (Nausieda et al., 1980).

Sodium valproate may enhance physiological release of $\mathrm{GABA}$ as well as possible inhibiting its degradation. In doses of $1200 \mathrm{mg}$ added to levodopa valproate had no clinical effect (Price et al., 1978) whereas doses of $2800 \mathrm{mg}$ per day have been reported to exacerbate levodopa-dyskinesias (Nutt et al., 1979).

Progabide, a putative GABA prodrug, was originally reported to reduce involuntary movements caused by levodopa and allow higher doses of L-dopa to be used with better control of parkinsonism (Bartholini et al., 1979). However, in a doubleblind placebo-controlled study Sheehy and colleagues (1981) found no effect on parkinsonian disability or levodopa-induced dyskinesias.

To date this approach has been disappointing. One reason for these poor results may be the wide-spread distribution of GABAergic systems and the failure of the presently available drugs to selectively influence basal ganglia activity.

\section{Peptides}

Experimental evidence exists to suggest that enkephalin/ endorphinergic neurons terminate presynaptically on dopaminergic nerve endings in the striatum (Pollard et al., 1977). Endorphins induce catalepsy, akinesia and rigidity in animals which can then be reversed by the opiate antagonist naloxone, as well levodopa or apomorphine (Bloom et al., 1976, Cuello and Paxinos, 1978). For these reasons it has been proposed that enkephalin receptors on dopaminergic neurons may modulate the release of dopamine. Based on this hypothesis both short(naloxone, IV) and long-acting (naltrexone, orally) opiate antagonists have been used in Parkinsonism. Nutt and his colleagues (1978) were unable to demonstrate an effect of oral naltrexone. They pointed out that the doses used (100 mg per day for 10 days) may have been insufficient to block the appropriate striatal opiate receptors. Naloxone has also failed to improve the major signs of Parkinsonism (Price et al., 1979; Trabucchi et al., 1982) and dyskinesias (Price et al., 1979) however Trabucchi and colleagues found a significant improvement in patients with the "on-off" phenomenon (probably not true "on-off" from their description of the stability of frequency and severity of fluctuations). Transitions from "on" to "off" became more gradual, the total "on" time increased and levodopainduced dyskinesias decreased. To explain the latter observation they pointed out that naloxone also partially reverses apomorphine-induced stereotyped behaviours in rats, possibly via nondopaminergic mechanisms (Trabucchi et al., 1982). 
Studler and colleagues (1982) have found that cholecystokinin (CCK) is selectively depleted in the substantia nigra in Parkinson's disease and administration of CCK has been reported to reverse reserpine-induced Parkinsonian features in animals (Diamond et al., 1982). Diamond and collegues suggest that analogues of CCK may be useful in the treatment of Parkinson's disease in the future.

The tripeptide PGL (Pro-Leu-Gly- $\mathrm{NH}_{2}$ ) previously known as melanocyte-stimulating hormone release-inhibiting factor(MIF-I) has been found to potentiate the actions of levodopa and oxytremorine in animals (Plotnikoff and Kastin, 1974). Although oral therapy with this agent has resulted in insignificant changes in Parkinsonian scores, intravenous use in doses of up to $400 \mathrm{mg}$ per day has been effective in improving the features of Parkinsonism in untreated patients and particularly in potentiating the effects of L-dopa therapy (Barbeau et al., 1979). Barbeau and Kastin (1976) postulated that the action of this compound is probably one of modulation of the post-synaptic dopamine receptor rather than modification of brain distribution, turn over, metabolism or release and uptake of catecholamines. Chase and his colleagues (cf Pelton and Chase, 1975) obtained no benefit with lower doses of PLG or with thyrotopin-releasing hormone (TRH) in patients receiving levodopa.

Based on speculations that the effects of L-dopa on growth hormone $(\mathrm{GH})$ might account for the varying responses seen in patients on chronic levodopa therapy McDowell and colleagues (1979) studied intramuscular GH versus saline control in patients with fluctuations and dyskinesias. Unfortunately there was no effect on either of these complications.

\section{Non-medical therapy}

Although not included in this discussion, physiotherapy and speech therapy are important adjuvants to patient care. However, the degree to which these techniques can result in objective physical benefit, over and above psychological improvement, is not well defined.

Stereotactic neurosurgery still has a place in the treatment of Parkinson's disease in a small, highly select group of patients, usually with prominent drug-resistant tremor. Some authors have also used stereotactic thalamotomy in cases of severe L-dopa-induced dyskinesias. Siegfried (1980) argues that neurosurgery allows the continuation of drug therapy in higher doses and therefore avoids the expected loss of benefit which would normally result if dosage reduction were used to decrease the severity of involuntary movements. Although patients may obtain short-term improvement, the long-term results and complications of this approach have not been carefully studied. In the future, surgical therapy may be extended to include cerebral implantation of catecholamine producing cells (Perlow et al., 1979). At present, the benefit of this approach in Parkinson's disease is extremely speculative and unproven (Kolata, 1982).

This symposium has emphasized the "current concepts and controversies in Parkinson's disease". The more we learn of this condition and the functioning of the basal ganglia the more questions arise and the greater the number of potential therapeutic agents becomes. Although the continued search for new antiparkinsonian drugs must be encouraged, physicians should be continually mindful of the need to individualize therapy carefully if any success in treatment is to be achieved. In view of the large number of drugs available or being developed this is even more important now than in the pre-levodopa era when Schwab (1961) made the following pertinent comment: "There is no condition that requires a more individual and meticulous adjustment of medication for symptoms that does Parkinson's disease. I would categorically state that most of the failures of treatment by drugs, in this disease, are due to a lack of appreciation of this point by both the physician and the patient. It is true that even with the best co-operation and understanding and care on the part of the phsycian, it not always possible to achieve very satisfactory adjustments in drugs: but one can state that it is impossible to achieve any kind of adjustment if this type of meticulous individual arrangements are noi carried out."

\section{ACKNOWLEDGEMENTS}

Special thanks to Mrs. Anne Taylor for providing the Neuropsychological test data for the Figure, Dr. R.D.G. Blair for reviewing the text and making helpful suggestions, and Jane Murphy for typing the manuscript.

\section{REFERENCES}

Albert M (1978) Subcortical dementia In: Alzheimer's disease, Senile Dementia and Related Disorders. Edited by R. Katzman, R.D. Terry and K.L. Bick. Raven Press; New York. pp. 173-180.

Agid Y, Quinn N, Pollack P, Illas A, Destee A, Signoret JL, Lhermitte F (1981) The treatment of Parkinson's disease with dopaminergic agonists in combination with domperidone. In: Apomophine and other Dopaminergics Vol 2: Clinical Pharmacology, edited by GU Corsini and GL Gessa. Raven Press New York pp. 107-115.

Asnis G (1977) Parkinson's disease, depression and ECT: A review and case study. Am. J. Psychiatry 134: 191-195.

Balldin J, Edén S, Granérus AK, Modign K, Svanborg A, Walinder J, Wallin L (1980) Electroconvulsive therapy in Parkinson's syndrome with "on-off" phenomenum. J. Neural. Transm. 47: 11-21.

Barbeau A (1962) The Pathogenesis of Parkinson's disease: A new hypothesis. Can. Med. Ass. J. 87: 802-807.

Barbeau A (1979) Lecithin in Movement disorders. In: Nutrition and the Brain. Volume 5 edited by A Barbeau, JH Growdon, and RJ Wurtman Raven Press, New York pp. 263-271.

Barbeau A, Kastin AJ (1976) Polypeptide therapy in Parkinson's disease - a new approach. In: Advances in Parkinsonism, edited by $W$ Birkmayer and O Hornykiewicz Editions Roche, Basel pp. 483-487.

Barbeau A, Roy M, Gonce M, Labrecque R (1979) Newer therapeutic Approaches in Parkinson's disease. Adv. Neurol. 24: 433-450.

Bartholini G, Lloyd KG, Worms P, Constantinides J, Tissot R (1979) GABA and GABA-ergic medication: relation to Striatal dopamine function and Parkinsonism. Adv. Neurol. 24: 253-257.

Beasley BL, Nutt JG, Chase TN (1980) Treatment with Tryptophan of levodopa-associated psychiatric disturbances. Arch. Neurol. 37: 155-156.

Bédard P, Parkes JD, Marsden CD (1978) Effect of new dopamineblocking agent (oxiperomide) on drug induced dyskinesias in Parkinson's disease and sponteneous diskinesias. Brit. Med. J. 1: 954-956.

Bédard P, Parkes JD, Marsden CD (1977) Normifensine in Parkinson's disease Br. J. Clin. Pharmacol. 4: 1875-1905.

Birkmayer W, Hornykeiwicz O (1962) Der L-Dioxyphenylalanin ( = DOPA) - Effekt Beeim Parkinson - syndrom des menschen: Zur pathogenese und behandlung des Parkinsons-akinese. Arch Psychiat Nervenk 203: 560-574.

Birkmayer W, Neumayer E (1972) Die behandlung der Dopa psychosen mit L-Tryptophan. Der Nervenarzt 43: 76-78.

Birkmayer W, Riederer P, Youdim MBH, Linauer W (1975) The potentiation of the anti-akinetic effect after L-dopa treatment by an inhibitor of MAO-B, deprenyl. J. Neural. Transm. 36: 303-326.

Birkmayer W, Riederer P, Ambrozi L, Youdim MBH (1977) Implications of combined treatment with "Madopar" and L-deprenyl in Parkinson's disease. Lancet 8019: 439-443. 
Birkmayer W, Riederer P, Youdim MBH (1982) (-) Deprenyl in the treatment of Parkinson's disease. Clin Neuropharmacology 5: 195-230.

Bloom F, Sagal D, Ling N, Guilleman R (1976) Endorphins: profound behavioural effects in rats suggest new etiological factors in mental illness. Science 194: 630-632.

Bowery NG, Hill DR, Hudson AL, Doble AL, Middlemiss DN, Shaw J, Turnbull M (1980) (-) Baclofen decreases neurotransmitter release in the mammalian CNS by an action at a novel GABA receptor. Nature 283: 92-94.

Broll M, Eymard P, Ferrandes B, Werbenec JP (1977) Pharmacologie d'un nouvel anti-parkinsonian, la diprobutine (LCG 21519) J Pharmacol 8: 524-525.

Bryant RC (1980) Duration of illness and response to tryptophan in Parkinson's disease. Arch. Neurol. 37: 677.

Burke RE, Fahn S (1982) Pharmocokinetics of trihexyphenidyl after acute and chronic administration. Ann. Neurol. 12: 94.

Clane DB, Reid JL, Vakil SD (1972) Parkinsonism treated with 3-0-methyldopa. Clin. Pharm. Therap. 14: 386-389.

Casey DE (1978) Amantadine intoxication reversed by physostigmine. N. Engl. J. Med. 298: 516.

Chase TN (1974) Serotonergic mechanisms and extrapyramidal function in man. Adv. Neurol. 5: 31-39.

Coffey CE, Ross DR, Ferren EL, Sullivan JL, Olanow CW (1982) Treatment of the "on-off" phenomenon in parkinsonism with lithium carbonate. Ann. Neurol. 12: 375-379.

Coyle JT, Snyder SH (1969) Antiparkinsonian drugs: Inhibition of dopamine uptake in the corpus striatun as a possible mechanism of action. Science 166: 899-901.

Cuello AC, Paxinos G (1978) Evidence for a long leu-encephalin striopallidal pathway in rat brain. Nature 271: 178-180.

Curtius H-Ch, Niederwieser A, Levine RA, Lovenberg W, Woggon B, Angst J (1983) Successful treatment of depression with Tetrahydrobiopterin. Lancet 1: 657-658.

Davies P, Maloney AJF (1976) Selective loss of central cholinergic neurones in Alzheimer's disease. Lancet 2: 1403.

Davis PL, Stewart WB (1938) The use of benzedrine sulfate in postencephalitic parkinsonism. JAMA 110: 1890-1892.

De Smet Y, Ruberg M, Serdaru M, Dubois B, Lhermitte F, Agid Y (1982) Confusion, dementia and anticholinergics in Parkinson's disease. J. Neurol. Neurosurg. Psychiatry 45: 1161-1164.

Diamond BI, Hitri A, Borison RL, Passinetti G (1982) The Role of cholecystokinin in the striatum: implications in Parkinson's disease. Ann. Neurol. 12: 98.

DiMascio A, Bernardo DL, Greenblatt DJ, Marder JE (1976) A controlled trial of Amantadine in drug-induced extrapyramidal disorders. Arch Gen. Psychiatry 33: 599-602.

Duvoisin RC (1967) Cholinergic-anticholinergic antagonism in Parkinsonism. Arch. Neurol. 17: 124-136.

Eisler T, Teräväinen H, Nelson R, Krebs H, Weise V, Lake CR, Ebert MH, Whetzel N, Murphy DL, Kopin IJ, Clane DB (1981) Deprenyl in Parkinson's disease. Neurology (NY) 31: 19-23.

Ericsson AD (1971) Potentiation of the L-dopa effect in man by the use of catechol-O-methyltransferase inhibitors. J. Neurol. Sci. 14: 193-197.

Fahn S (1982) In: The management of Parkinson's disease at different stages of the illness. Clin. Pahrmacol. 5(1) p. 59.

Fahn S, Craddock G, Kumin G (1971) Acute toxic psychosis from suicidal overdosage of Amantadine. Arch. Neurol. 25: 45-48.

Fahn S, Libsch LK, Cutler RW (1971a) Momoamines in the human neostriatum: Topographic distribution in normals in Parkinson's disease and their role in akinesia, rigidity, chorea and tremor. J. Neurol. Sci. 14: 427-455.

Farnebo L, Fuxe K, Hamberger B, Ljungdahl H (1970) Effect of some antiparkinsonian drugs on catecholamine neurons. J. Pharm. Pharmacol. 22: 733-737.

Foster NL, Newman RP, LeWitt PA, Gillespie MM, Chase TN, Larsen TA (1983) Beta blockade of Parkinsonian Tremor. Ann. Neurol. 14: 134.

Gerlak RP, Clark R, Stump JM, Vernier VG (1970) Amantadine-dopamine interaction. Science 169: 203-204.

Gerstenbrand F, Rainer J, Poewe W (1979) The influence of B adrenergic blocking agents on Parkinson Synsdrome. Can. J. Neurol. Sci. 6: 79.

Gervas JJ, Muradás V, Bazán E, Aguado EG, de Yébenes JG (1983) Effects of 3-OM-dopa on monoamine metabolism in rat brain. Neurology 33: 278-282.
Goetz CG, Nausiedad PA, Weiner WH, Klawans HL (HL) (1981) Practical guidelines for drug holidays in parkinsonian patients. Neurology (NY) 31: 641-642.

Goetz CG, Tanner CM, Klawans KL (1983) Bupropion-HCl in idiopathic Parkinson's disease. Neurology 33 (2): 123.

Greenfield JG, Bosanquet FD (1953) The brain-stem lesions in parkinsonism. J. Neurol. Neurosurg. Psychiatry 16: 213-226.

Growden JH (1981) Tyrosine treatment in Parkinson's disease: clinical effects. Neurology (NY) 31(2) 134.

Halliday AM, Nathan PW (1961) Methylphenidate in Parkinsonism. Brit Med. J. 1: 1652-1655.

Heel RC, Morley PA, Brogden RN, Carmine AA, Speight TM, Avery GS (1982) Zimelidine: A review of its pharmacological properties and therapeutic efficacy in depressive illness. Drugs 24: 169-206.

Horrocks PM, Vicary DJ, Rees JE, Parkes JD, Marsden CD (1973) Anticholinergic withdrawl and benzhexol treatment in Parkinson's disease. J. Neurol. Neurosurg. Psychiatry 36: 936-941.

Hughes RC, Polgar JG, Weightman D, Walton JN (1971) Levodopa in Parkinsonism: the effects of withdrawal of anticholinergic drugs. Brit. Med. J. 2: 487-491.

Hunt P, Kannengiesser MH, Raynaud JP (1974) Nomifensine a new potent inhibitor of dopamine uptake into synaptosomes from rat brain corpus striatum. J. Pharm. Pharmacol. 26: 370-371.

Hunter KR, Boakes AJ, Lawrence DR, Stern GM (1970) Monoamine oxidase inhibitors and L-dopa. Brit. Med. J. 3: 388.

Hurtig HI (1980) Anticholinergics for Parkinson disease. Ann. Neurol. 7: 495

Jefferson D, Jenner P, Marsden CD (1979) B-Adrenoreceptor antagonists in essential tremor. J. Neurol. Neurosurg. Psychiatry 42: 904-909.

Jenner P, Elliott P, Clow A, Reavil C, Marsden CD (1978) A comparison of in vitro and in vivo dopamine receptor antagonism produced by substituted benzamide drugs. J. Pharm. Pharmacol. 30: 46-48.

Karobath M, Diaz J, Huttunen M (1971) The effect of L-dopa on the concentration of tryptophan, tyrosine and serotonin in rat brain. Eur. J. Pharmacol. 14: 393-396.

Karoum F, Chuang L, Eisler T, Clane DB, Liebowitz MR, Quitkin FM, Klein DF, Wyatt RJ (1982) Metabolism of (-) deprenyl to amphetamine and methamphetamine may be responsible for deprenyl's therapeutic benefit: A biochemical assessment. Neurology (NY) 32: 503-509.

Klawans HL (1982) Behaviour alterations and the therapy of Parkinsonism. Clin Neuropharmacol 5 (Suppl 1): 529-537.

Klawans HL, Rubovits R (1972) Central Cholinergic - anticholinergic antagonism in Huntington's chorea. Neurology 22: 107-116.

Klawans HL, Topel JL, Bergen D (1975) Deanol in the treatment of levodopa-induced dyskinesias. Neurology 25: 290-293.

Knoll $\mathbf{J}(1978)$ The possible mechanism of action of (-) deprenyl in Parkinson's disease. J. Neural. Transm. 43: 177-198.

Kolata G (1982) Grafts correct brain damage. Science 27: 342-344.

Lang AE (in press) Lithium and parkinsonism. Ann. Neurol.

Lebensohn ZM, Jenkins RB (1975) Improvement of Parkinsonism in depressed patients treated with ECT. Am. J. Psychiatry 132: 283-285.

Lees AJ, Shaw KM, Kohout LJ, Stern GM, Elsworth JD, Sandler M, Youdim MBH (1977) Deprenyl in Parkinson's disease. Lancet 2: $791-796$.

Lees AJ, Shaw KM, Stern GM (1978) Baclofen in Parkinson's disease. J. Neurol. Neurosurg. Psychiatry 41: 707-708.

Lees AJ. Lander CM, Stern GM (1979) Tiapride in levodopa-induced involuntary movements. J. Neurol. Neurosurg Psychiatry 42: 380-383.

Lhermitte F, Signoret JL, Agid Y (1977) Étude des effets d'une molecule originale, le tiapride dans le traitement des mouvements anormaux d'origine extrapyramidale. Sem. Hop. Paris 53: 9-15.

Lieberman A, Gopinathan G (1982) Treatment of "on-off" phenomena with lithium. Ann. Neurol. 12: 402.

Lindeboom SF, Lakke JPWF (1978) Deanol and physostigmine in the treatment of L-dopa-induced dyskinesias. Acta neurol. Scandinav. 58: $134-138$.

Lloyd KG, Shemen L, Hornykiewicz O (1977) Distribution of high affinity sodium-dependent $\left({ }^{3} \mathrm{H}\right)$ gamma-aminobutyric acid $\left({ }^{3} \mathrm{H}-\mathrm{GABA}\right)$ binding in the human brain: alteration in Parkinson's disease. Brain Res. 127: 269-278.

Mayeux R, Stern Y, Cote L, Williams JBW (1983) Clinical and biochemical features of depression in Parkinson's disease. Ann. Neurol. 14: 135.

McDowell FH, Papavasiliou P, Sweet R (1979) Long-term study and the effect of human growth hormone in Parkinsonian patients treated with levodopa. Adv. Neurol. 24: 475-488. 
Mendlewicz J, Youdim MBH (1983) L-deprenyl, a selective monoamineoxidase Type $B$ inhibitor in the treatment of depression: A double blind evaluation. Brit. J. Psychiat. 142: 508-511.

Miller E (1974) Deanol in the treatment of levodopa-induced dyskinesias. Neurology 24: 116-119.

Miller EM, Nieburg HA (1974) L-tryptophan in the treatment of levodopa induced psychiatric disorders. Dis. Nerv. Syst. 35: 20-23.

Muenter MD, Sharpless NS, Tyce GM (1972) Plasma 3-O-methyldopa in L-DOPA therapy of Parkinson's disease. Mayo. Clinic Proc. 47: 389-395.

Muenter MD, Sharpless NS, Tyce GM (1974) 3-O-methydopa in Parkinson's disease. Adv. Neurol. 5: 309-315.

Nagatsu T, Kato T, Nagatsu I, Kondo Y, Inagaki S, lizuka R, Narabayashi H (1979) Catecholamine related enzymes in the brain of patients with Parkinsonism and Wilson's disease. Adv. Neurol. 24: 283-292.

Narabayashi H, Kondo T, Hayashi A, Suzuki T, Nagatsu T (1981) L-Threo-3, 4-Dihydroxyphenylserine treatment for akinesia and freezing in Parkinsonism. Proc. Japan Acad. 57: (Ser B): 351-354.

Narabayashi H, Kondo T, Nagatsu T, Sugimoto T, Matsuura S (1982) Tetrahydrobiopterin administration for Parkinsonian symptoms. Proc. Japan Soc. 58 (Ser B): 283-287.

Nausieda PA, Koller WC, Weiner WJ, Klawans HL (1981) Pemolineinduced Chorea. Neurology (NY) 31: 356-360.

Nausieda PA, Tanner CM, Klawans HL (1983) Serotonergically active agents in levodopa-induced psychiatric toxicity reactions. Adv. Neurol. 37: 23-32.

Nausieda PA, Weiner, WJ, Klawans HL (1980) Dystonic foot response of Parkinsonism. Arch. Neurol. 37: 132-136.

Nutt JG, Rosin AJ, Eisler T, Calne DB, Chase TN (1978) Effect of an opiate antagonist on movement disorders. Arch. Neurol. 35: 810-811.

Nutt J, William A, Plotkin C, Eng N, Zeigler M, Calne DB (1979) Treatment of Parkinson's disease with Sodium valproate: Clinical pharmacological and biochemical observations. J. Can. Neurol. Sci. 6:337-343.

Ordenstein L (1867) Sur la paralysie agitante et la sclérose en plaque généralisé. Martinet, Paris.

Owen DAL, Marsden CD (1965) Effect of B-Blockade in parkinsonian tremor. Lancet 2: 1259-1262.

Papavasiliou PS, Rosal V (1979) Effects of Choline in patients with levodopa-induced dyskinesias. In: Nutrition and the Brain Vol. 5. Edited by A. Barbeau, JH Growden, and RJ Wurtman. Raven Press, New York pp. 335-341.

Park DM, Findley LJ, Hanks G, Sandler M (1981) Nomifensine effect in Parkinsonian patients not receiving levodopa. J. Neurol. Neurosurg. Psychiatry 44: 352-354.

Parkes JD (1974) Amantadine. Adv. Drug. Res. 5: 11-81.

Parkes JD, Baxter RC, Glabraith A, Marsden CD, Rees JE (1973) Amantadine treatment in Parkinson's disease. Adv. Neurol. 3: 105-114.

Parkes JD, Baxter RC, Marsden CD, Rees JE (1974) Comparative trial of benzhexol, amantadine and levodopa in the treatment of Parkinson's disease. J. Neurol. Neurosurg. Psychiatry 37: 422-425.

Parkes JD, Tarsy D, Marsden CD, Bovill KT, Phipps JA, Rose P, Asselman P (1975) Amphetamines in the treatment of Parkinson's disease. J. Neurol. Neurosurg. Pshyciatry 38: 232-237.

Pelton EW Il, Chase TN (1975) L-dopa and the treatment of extrapyramidal disease. Adv. Pharmacol Chemotherapy 13: 253-302.

Perlow MJ, Freed WJ, Hoffer BJ, Seiger A, Olson L, Wyatt RJ (1979) Brain grafts reduce motor abnormalities produced by destruction of nigrostriatal dopamine system. Science 204: 643-647.

Plotnikoff NP, Kastin AJ (1974) Pharmacological studies with a tripeptide, prolyl-leucyl-glycine amide. Arch. Int. Pharmacoldyn Ther. 211: $211-224$.

Pollard H, Liorens-Cortes C, Schwartz JC (1977) Encephalin receptors on dopaminergic neurones in rat striatum. Nature 268: 745-747.

Price P, Baxter RCH, Parkes JD, Marsden CD (1979) Opiate antagonists and Parkinson's disease. Arch. Neurol. 36: 661.

Price PA, Parkes JD, Marsden CD (1978) Solium valproate in the treatment of levodopa-induced dyskinesia. J. Neurol. Neurosurg. Psychiatry 41: 702-706.

Price P, Parkes JD, Marsden CD (1978a) Tiapride in Parkinson's disease Lancet 2: 1106.

Price P, Schacter M, Bédard P, Parkes JD, Marsden CD (1981), DA receptor antagonists in Parkinson's disease. In: Research progress in Parkinson's disease. Edited by FC Rose and R Capildeo. Pitman Medical Tunbridge Wells pp. 318-323.
Reches A, Fahn S (1982) 3-O-methyldopa blocks DOPA metabolism in rat corpus striatum. Ann. Neurol. 12: 267-271.

Reches A, Fahn S (1983) Lithium in the "on-off" phenomenom. Ann. Neurol. 14: 91-92.

Reches A, Jackson-Lewis V. Fahn S (1983) DL-threo-dihydroxyphenylserine as a precursor of norephinepherine. Ann. Neurol. 14: 137.

Reynolds EP, Riederer R, Sandler M, Jellingter K. Seeman D (1978) Amphetamine and 2-phenylethylamine in post-mortem parkinsonian brain after (-) deprenyl administration. J. Neural. Transm. 43: 271-277.

Rinne UK (1978) Recent advances in research on parkinsonism. Acta. Neurol. Scandinav. 57 (suppl. 67): 77-113.

Rinne UK, Sonninen V (1973) Brain catecholamines and their metabolites in Parkinsonian patients. Arch. Neurol. 28: 107-110.

Rinne UK, Sonninen V, Riekkinen P, Laadsonen H (1974) Postmortem findings in parkinsonian patients treated with L-dopa: Biochemical considerations. In: Current concepts in the treatment of Parkinsonism. edited by MD Yahr Raven Press, New York pp. 211-233.

Rinne UK, Sürtola T, Sonninen V (1978) (-) Deprenyl treatment of on-off phenomena in Parkinson's disease. J. Neural. Transm. 43: 253-262.

Rivera-Calimlim L, Tandon D, Anderson F, Joynt R (1977) The clinical picture and plasma levodopa metabolite profile of parkinsonian non-responders. Treatment with levodopa and decarboxylase inhibitor. Arch. Neurol. 34: 228-232.

Ruberg M, Ploska A, Javoy-Agid F, Agid Y (1982) Muscarinic binding and choline acetyltransferase activity in Parkinsonian subjects with reference to dementia. Brain Res. 232: 129-139.

Sadeh M, Braham J, Modan M (1982) Effects of anticholinergic drugs on memory in Parkinson's disease. Arch. Neurol. 39: 666-667.

Sandler M, Stern GM (1981) Deprenyl in Parkinson's disease. In: Movements Disorders. Edited by CD Marsden and S Fahn Butterworth Scientific, London pp. 166-173.

Sandler M, Youdim MBH (1974) Monoamine oxidase: The present status. Int. Pharmacopsychiatr. 9: 27-34.

Schacter M, Marsden CD. Parkes JD, Jenner P. Testa B (1980) Deprenyl in the management of response fluctuations in patients with Parkinson's disease on levodopa. J. Neurol. Neurosurg. Psychiatry 43: 1016-1021.

Schwab RS (1961) Symptomatology and medical treatment of Parkinson's disease. Int. J. Neurol. 2: 61-75.

Schwab RS, Chafety ME (1955) Kemadrin in the treatment of Parkinsonism. Neurology (Minneap) 5: 273-277.

Schwab RS, England AC Jr. (1969) Amantadine HCL (Symmetrel) and its relation to levo-dopa in the treatment of Parkinson's disease. Trans. Am. Neurol. Assoc. 94: 85-90.

Schwab RS, England AC, Poskanzer DC, Young RR (1969) Amantadine in the treatment of Parkinson's disease. JAMA 208: 1168-1170.

Schwab RS, Poskanzer DC, England AC, Young RR (1972) Amantadine in Parkinson's disease. Review of more than two years experience. JAM A 222: 792-795.

Sharpless NS, McCann DS (1971) DOPA and 3-O-methydopa in cerebrospinal fluid in Parkinsonian patients during treatment with oral L-DOPA. Clin Chim Acta 31: 155-169.

Sheehy MP, Schacter M, Parkes JD, Marsden CD (1981) GABAmimetics, Parkinson's disease and other movement disorders. $I n$ : Research progress in Parkinson's Disease. Edited by Rose FC, Capildeo R. Pitman Medical Tunbridge Wells pp. 309-317.

Siegfried J (1980) Is the neurosurgical treatment of Parkinson's Disease still indicated? J. Neural. Trans. suppl. 16: 195-198.

Sign BK, Singh A, Chusid E (1983) Chorea in long-term use of pemoline. Ann. Neurol. 13: 218.

Stern GM (1980) Current adjuvants to levodopa therapy. In: Parkinson's disease-current progress, problems and management. Edited by UK Rinne, M Klinger and G Stamm Elsevier/North Holland Bio. Med. Press pp. 357-361.

Stone TW (1977) Evidence for a non-dopaminergic action of amantadine Neuro. Sci. Lett 4: 343-346.

Strang RR (1965) Kemadrin in the treatment of Parkinsonism: a double blind and one year follow-up study. Current Medicine and Drugs 5: 27-32.

Strang RR (1965a) Experiences with congentin in the treatment of Parkinsonism. Acta Neurol. Scandinav. 41: 413-418.

Studler JM, Javoy-Agid F, Cesselin F, Legrand JC, Agid Y (1982) CCK-8-Immunoreactivity distribution in human brain: selective decrease in the substantia nigra from Parkinsonian patients. Brain Research 243: 176-179. 
Syndulko K, Gilden ER. Hansch EC, Potvin AR, Tourtellotte WW, Potvin JH (1981) Decreased verbal memory associated with anticholinergic treatment in Parkinson's disease patients. Int. J. Neurosci. 14: 61-66.

Tanner CM, Goetz CG, Klawans HL (1982) Paraxysmal drenching sweats in idiopathic Parkinsonism: response to propranolol. Neurology (NY) 32 (2): A162.

Tarsy D, Leopold N, Sax D(1973) Physostigmine in choreiform movement disorders. Neurology (Minneap) 23: 392-393.

Tarsy D, Parkes JD, Marsden CD (1975) Clonidine in Parkinson's disease. Arch. Neurol. 32: 134-136.

Tarsy D, Parkes JD, Marsden CD (1975a) Metoclorpramide and pimozide in Parkinson's disease and levodopa-induced dyskinesias. J. Neurol. Neurosurg. Psychiatry 38: 331-335.

Teychenne PF, Park DM, Findley LJ, Fose FC, Calne DB (1976) Nomifensine in parkinsonism. J. Neurol. Neurosurg. Psychiatry 39: 1219-1221.

Teychenne PF, Ziegler MG, Lake CR, Enna SJ (1982) Low CSF GABA in Parkinsonian patients who respond poorly to therapy or suffer from the "on-off" phenomenon. Ann. Neurol. 11: 76-79.
Trabucchi M, Bassi S, Frattola L (1982) Effect of naloxone on the "on-off' syndrome in patients receiving long-term levodopa therapy. Arch. Neurol. 39: 120-121.

Weintraub MI, Van Woert MH (1971) Reversal by levodopa of cholinergic hypersensitivity in Parkinson's disease. N. Engl. J. Med. 284: 412-415.

Whitehouse PJ, Hedreen JC, White CL, Price DL (1983) Basal forebrain neurones in the dementia of Parkinson's disease. Ann. Neurol. 13: 243-248.

Whitehouse PJ, Price DL, Clarke AW, Coyle JT, DeLong MR (1981) Alzheimer's disease: evidence for selective loss of cholinergic neurones in the Nucleus Basalis. Ann. Neurol. 10: 122-126.

Yahr MD, (1978) Overview of present day treatment of Parkinson's disease. J. Neural. Trasm. 43: 227-238.

Yahr MD, Clough CG, Bergmann KJ (1982) Cholinergic and dopaminergic mechanisms in Parkinson's disease after long term levodopa administration Lancet 2: 709-710.

Yang HYT, Neff NH (1973) Beta-phelethylamine: A specific substrate for type B momoamine oxidase of brian. J. Pharmacol. Exp. Ther. 187: $365-371$. 